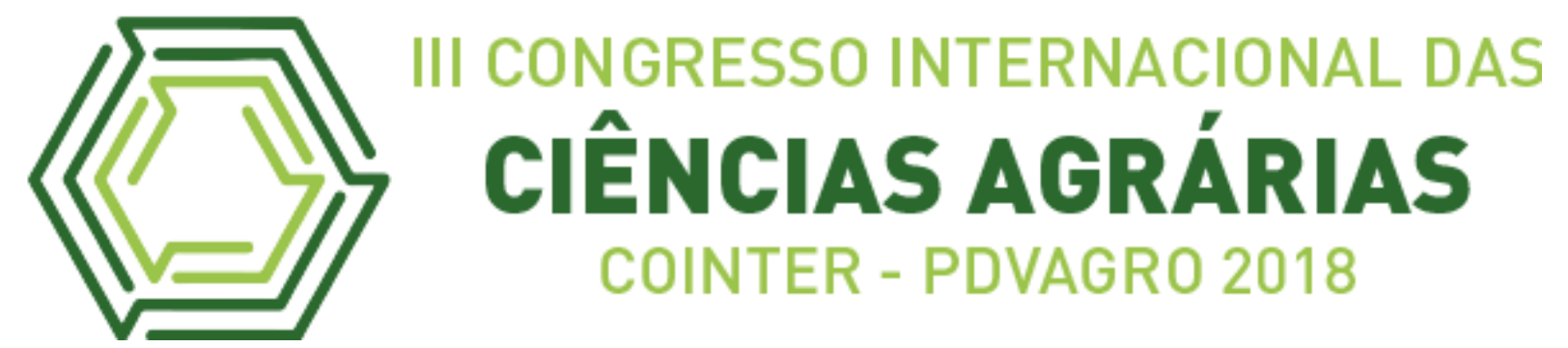

\title{
RETENÇÃO DE ÁGUA EM CLASSES DE SOLO NO OESTE POTIGUAR EM ASSOCIAÇÃO COM AS FRAÇÕES INORGÂNICAS DO SOLO
}

\section{WATER RETENTION IN SOIL CLASSES IN THE WEST POTIGUAR IN ASSOCIATION WITH INORGANIC SOIL FRACTIONS}

\author{
Apresentação: Pôster
}

Francisco Wellington Andrade Silva ${ }^{1}$; Jeane Cruz Portela ${ }^{2}$; Antonio Carlos da Silva ${ }^{3}$; Max Andrez de Souza Oliveira ${ }^{4}$; Phâmella Kalliny Pereira Farias ${ }^{5}$

\section{DOI: $\underline{\text { htps://doi.org/10.31692/2526-7701.IIICOINTERPDVAGRO.2018.00657 }}$}

\section{Introdução}

A curva de retenção de água do solo (CRA) é representada pela relação entre a quantidade de água que o solo pode reter, em um dado valor do potencial mátrico, a partir dos fenômenos de capilaridade e adsorção. Quanto mais próximo da capacidade de campo, onde os microporos encontram-se preenchidos por água, a capilaridade terá influência e, quanto mais seco o solo, maior será o efeito da adsorção (LIBARDI, 2012).

A determinação CRA é muito importante do ponto de vista agrícola para o entendimento da dinâmica da água, sendo utilizada como ferramenta na descrição do comportamento físico-hídrico do solo, uma vez que permite quantificar a retenção e disponibilidade de água às plantas, por meio dos índices porosidade, capacidade de campo (CC), ponto de murcha permanente (PMP), água disponível (AD), se constituindo em um indicador de qualidade física essencial ao desenvolvimento vegetal (DEBNATH et al., 2012).

Diante do exposto, o objetivo do presente trabalho foi estudar a curva de retenção de água em associação com as frações inorgânicas em, no Projeto de Assentamento (P.A) Terra

\footnotetext{
${ }^{1}$ Graduando em Agronomia, Universidade Federal Rural do Semiárido-UFERSA, fwellingtonas@gmail.com

${ }^{2}$ Professora da Universidade Federal Rural do Semiárido-UFERSA, jeaneportela@ufersa.edu.br

${ }^{3}$ Técnico Administrativo, Universidade Federal Rural do Semiárido-UFERSA, antoniocarlos@ufersa.edu.br

${ }^{4}$ Graduando em Agronomia, Universidade Federal Rural do Semiárid0- UFERSA, maxandrezoliveira@yahoo.com.br

${ }^{5}$ Doutorando em manejo de Solo e Água, Universidade Federal Rural do Semiárido UFERSA, phamellakalliny@hotmail.com
} 
de Esperança em Governador Dix Sept Rosado-RN, tendo em vista apontar distinção dos ambientes utilizando a técnica de estatística multivariada.

\section{Fundamentação Teórica}

A curva de retenção de água no solo (CRAS) é influenciada por diversos fatores, e dentre eles os atributos físicos do solo, como a textura e teor de matéria orgânica, bem como distribuição de poros (KLEIN; KLEIN, 2015). Contudo, a textura apresentam efeitos mais pronunciados sobre a CRAS, sendo que solos de textura argilosa apresentam maior retenção se comparados a solos arenosos em função da predominância da argila que possuí cargas $\mathrm{s}$ negativas, atividade coloidal, área superficial específica alta e micro porosidade.

A fração orgânica atua indiretamente na CRAS, sendo dependente da textura, em devido modificações geradas pelo aporte orgânico na estrutura do solo, como agente agregante formando os agregados secundários, que se unem aos primários, devido ao material inorgânico, como um conjunto de partículas sólidas (MOTTA et al., 2008).

\section{Metodologia}

A pesquisa foi realizada no Projeto de Assentamento Terra de Esperança, em Governador Dix-Sept Rosado-RN. Foram selecionados 4 classes de solos, classificados em Latossolo (Perfil 1 P1); Chernossolo (P2); Neossolo (P3) e Cambissolo (P4). Cletou-se amostras deformadas e indeformadas posteriormente levadas ao Laboratório de Análises de Solo, Água e Planta do Centro de Ciências Agrárias da Universidade Federal Rural doSemiárido (LASAP-CCA-UFERSA).para realização das análises de granulometria e curva de retenção de água no solo (macro, micro, porosidade total e de aeração, Capacidade de Campo - CC, Ponto de Murcha Permanente - PMP e Água Disponível - AD).

A análise granulométrica foi realizada pelo método da pipeta, conforme Teixeira et al. (2017). Para a análise da macro, micro e porosidade total, as amostras foram saturadas por 48 horas e pesadas (para determinar a porosidade total), encaminhadas para mesa de tensão saturada com água, na tensão de $6 \mathrm{kPa}$ sendo a porosidade total do solo, (Pts) determinada medindo-se a umidade de saturação das amostras. A microporosidade foi determinada, pelo conteúdo de água retida no solo para o valor de h igual a $60 \mathrm{~cm}$ de água. A macroporosidade, foi determinada por meio da diferença entre a porosidade total e microporosidade do solo, 
conforme Teixeira et.al., (2017).

Para determinação das curvas de retenção, aplicou-se as tensões 0;2;6 e $10 \mathrm{kPa}$, câmaras de baixa tensão para os pontos 33 e $100 \mathrm{kPa}$ e de alta tensão para os pontos 200 e $1500 \mathrm{kPa}$, com base na equação de Van Genuchten (1980). O valor da CC foi definido na tensão de $10 \mathrm{kPa}$ (Latossolo) e $33 \mathrm{kPa}$ (para as demais),. O PMP, foi obtido com a tensão de $1500 \mathrm{kPa}$. A AD foi determinada pela diferença entre CC e PMP (TEIXEIRA et al., 2017).

Os resultados dos atributos físicos do solo forma expressos da média de quatro repetições por horizonte, nas respectivas classes, sendo interpretados por meio da técnica de análise multivariada como ferramenta principal, para distinção dos atributos mais sensíveis na distinção dos ambientes.

\section{Resultados e Discussões}

A tabela 1 estão expressas as correlações entre as variáveis estruturais estudadas. Correlações significativas foram encontradas, entre a Argila e a CC, PMP, Paeração, PTdet., Microp., e Macrop, evidenciando a influência da fração argila sobre os atributos estruturais, uma vez que esta é a fração ativa do solo, apresentando atividade coloidal alta e predominância de cargas negativas (BRADY e WEIL 2013).

Tabela 1: Matriz de correlação entre as variáveis dos atributos do solo nas áreas em estudo, no Projeto

\begin{tabular}{ccccccccccc}
\hline & Argila & AT & Silte & CC & PMP & AD & Paeração & $\theta$ & PTdet. Microp. Macrop. \\
\hline Argila & 1,00 & & & & & & & & \\
AT & $-0,16$ & 1,00 & & & & & & \\
Silte & $-0,51$ & $\mathbf{- 0 , 7 7}$ & 1,00 & & & & & \\
CC & $\mathbf{0 , 6 2}$ & $\mathbf{- 0 , 7 6}$ & 0,26 & 1,00 & & & & \\
PMP & $\mathbf{0 , 6 0}$ & $-0,29$ & $-0,14$ & 0,54 & 1,00 & & &
\end{tabular}




\begin{tabular}{ccccccccccccc} 
AD & 0,44 & $\mathbf{- 0 , 7 6}$ & 0,38 & 0,91 & 0,15 & 1,00 & & & & & \\
Paeração & $\mathbf{0 , 7 2}$ & $-0,32$ & $-0,19$ & $\mathbf{0 , 6 8}$ & $\mathbf{0 , 6 2}$ & 0,49 & 1,00 & & & & \\
$\theta$ & 0,22 & $-0,03$ & $-0,12$ & 0,34 & 0,49 & 0,17 & 0,06 & 1,00 & & & \\
PT det. & $\mathbf{0 , 5 5}$ & $-0,50$ & 0,08 & $\mathbf{0 , 7 9}$ & $\mathbf{0 , 6 3}$ & $\mathbf{0 , 6 3}$ & $\mathbf{0 , 8 5}$ & 0,27 & 1,00 & & \\
Microp. & $\mathbf{0 , 7 5}$ & $-0,40$ & $-0,14$ & $\mathbf{0 , 7 6}$ & $\mathbf{0 , 6 7}$ & $\mathbf{0 , 5 7}$ & $\mathbf{0 , 9 9}$ & 0,15 & $\mathbf{0 , 8 7}$ & 1,00 & \\
Macrop. & $\mathbf{- 0 , 6 5}$ & 0,02 & 0,40 & $-0,29$ & $-0,37$ & $-0,16$ & $\mathbf{- 0 , 6 4}$ & 0,11 & $-0,18$ & $\mathbf{- 0 , 6 5}$ & 1,00 \\
\hline
\end{tabular}

A AT obteve correlação negativa com o silte, $\mathrm{CC}$ e $\mathrm{AD}$, variáveis $\mathrm{CC}, \mathrm{PMP}, \mathrm{AD}$ e Paeração foram apresentaram-se de forma significativa com a PTdet, Microp. e Macrop.

Na Figura 1 A e B encontra-se representado o círculo de correlação (F1x F2) e a nuvem de variáveis, em que a sobreposição de ambos no plano fatorial, permite a visualização das variáveis que distinguem os ambientes, em estudo. Nesta conjectura, destacaram-se as variáveis $\theta$ e Argila, silte e macroporosidade foram responsáveis por distinguiram o ambiente de Cambissolo Háplico e Neossolo Flúvico, uma vez estas variáveis se concentram na nuvem de pontos no mesmo quadrante do plano, onde se agrupam os horizontes destas classes. Tal fato pode ser atribuído às frações inorgânicas (argila e areia) por apresentarem variabilidade em função dos fatores e processos de formação do solo. A fração argila apresentou correlação entre as variáveis de Ptdeter, Microp., Paeração e PMP (Tabela 2), fator atrelado às frações inorgânicas serem determinantes nas distinções dos ambientes.

Figura 1 - Círculo de correlação Fator 1 x Fator 2 (A) e Plano fatorial com a nuvem de variáveis Fator 1 x Fator 2 (B), mostrando a relação dos atributos do solo e as áreas em estudo.Fonte: própria

A

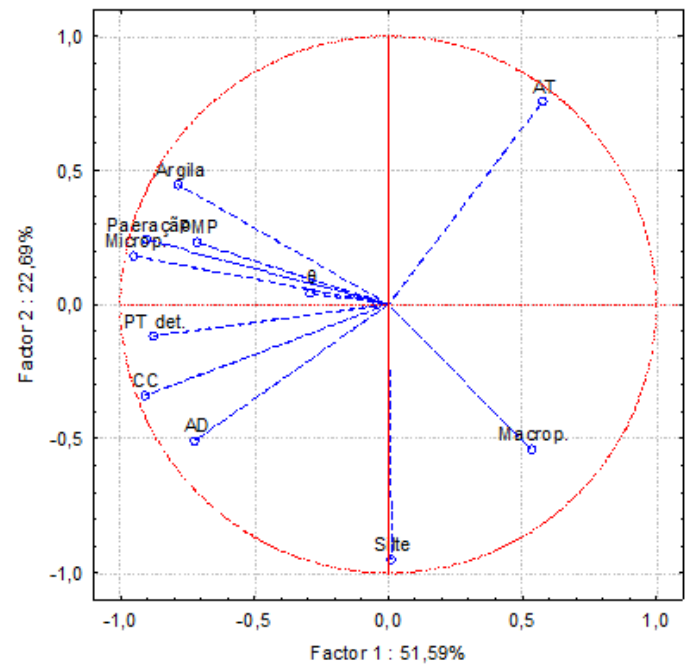

B

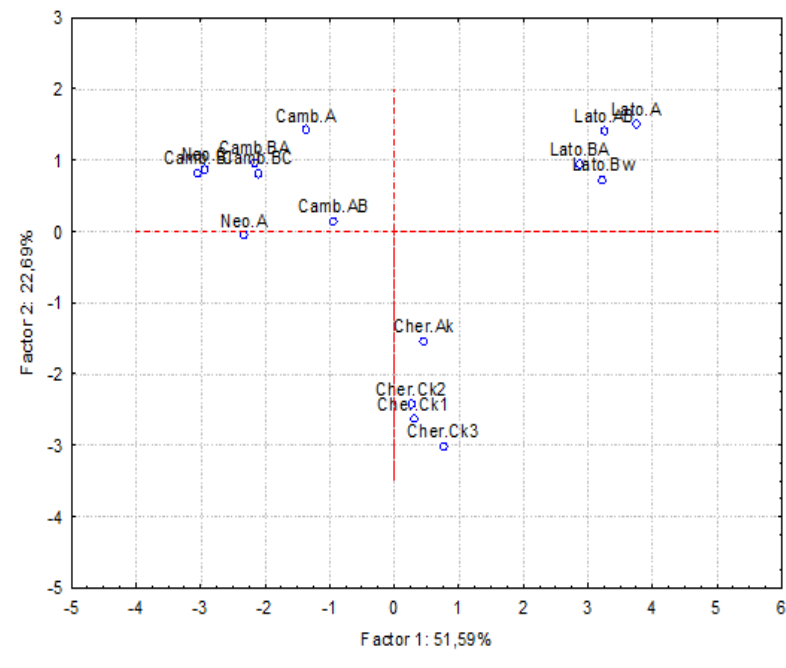

Ao analisar a classe do Latossolo, verifica-se separação deste ambiente para fração Areia total (AT), consequência do processo de latolização, que remove a sílica e as bases trocáveis, iluviando a argila em profundidade, conferindo boa drenagem (SANTOS et al., 
2013). Quanto ao Chernossolo, destaca-se o silte e a Macroporosidade (Figura 1 A e B), indicativo de solos jovens, pouco intemperizados e com deficiência de drenagem.

Quanto à retenção de água no solo, o Latossolo (Figura 3A) apresentou distinção das demais classes, com menores valores de água disponível para todos os horizontes. Essa tendência pode ser atribuída à composição granulométrica, predominantemente arenosa na superfície, em associação com predomínio da macroporosidade em detrimento da fração argila. Parahyba et al. (2015), constatou que em solos arenosos em que a areia grossa predomina sobre a fina, há limitação, ocorre menor à retenção e água disponível. Segundo Reichardt (1990), isso ocorre devido aos solos arenosos possuírem poros geralmente maiores e, consequentemente esvaziados mais rapidamente sob baixas tensões, restando pequenas quantidades de água retida sob potenciais menores.

Ao avaliar o Chernossolo (Figura 3B), verifica-se em superfície menor conteúdo de água disponível com aumento em subsuperficie, tal fator deve-se ao incremento da fração silte em profundidade, bem como a argila, principalmente, na profundidade de $50-120 \mathrm{~cm}$, correspondendo ao horizonte $\mathrm{Ck} 2$.

Figura 3. Curva de retenção de água no Latossolo, nos respectivos horizontes - A e, curva de retenção de água no Chernossolo Rêndzico, nos respectivos horizontes - B. Fonte: própria

A

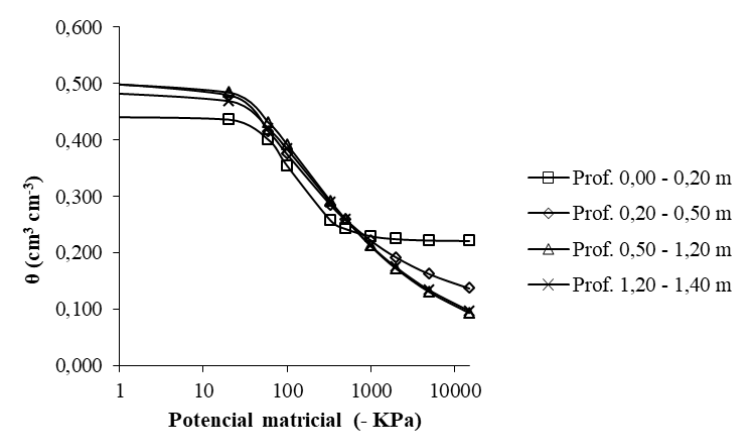

B

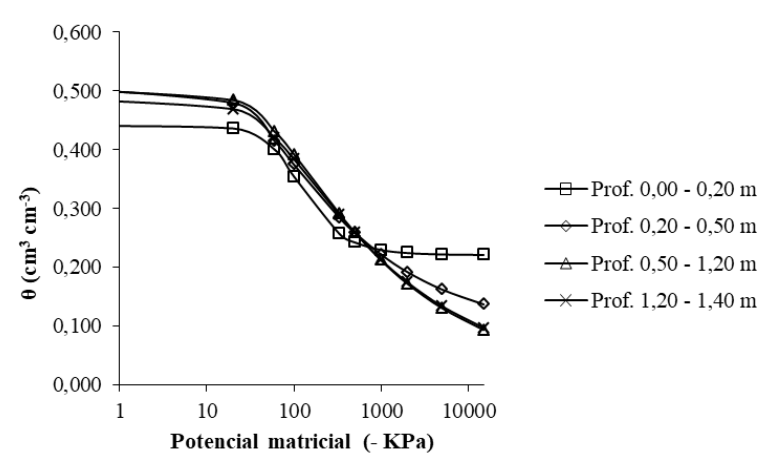

A curva característica de água no solo mostrou tendência de retenção similar entre a de Cambissolo (Figura 5 A) e Neossolo Flúvico (Figura 5 B), quanto aos atributos CC, PMP, AD e Өs.

Figura 5. Curva de retenção de água no Neossolo Flúvico (P3) - A, e Curva de retenção de água no Cambissolo Háplico (P4) nos respectivos horizontes - B. Fonte: Própria 
A

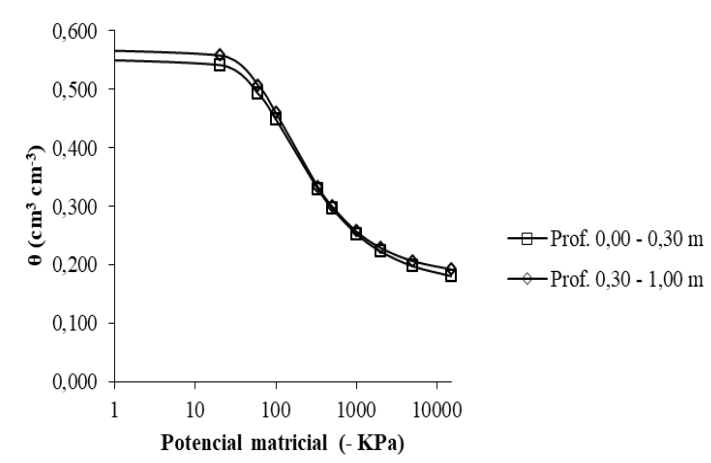

B

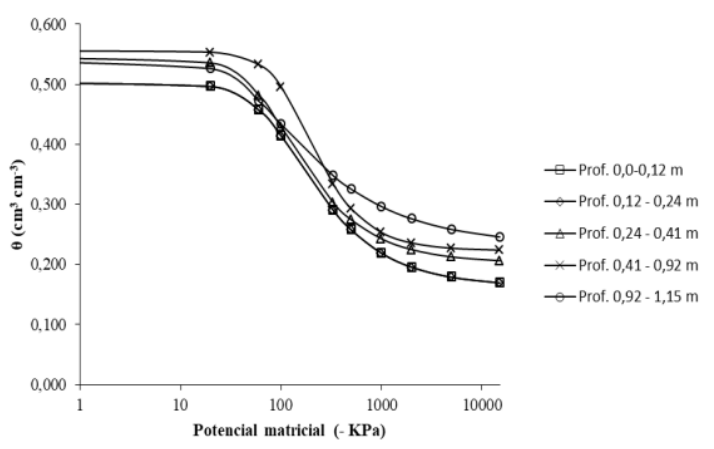

Este fato pode ser atribuído à predominância da argila, tanto no cambissolo quanto no Neossolo. Quanto ao Neossolo, há influência da posição do solo na paisagem, sendo área deposicional, recebendo sedimentos aluviais advindos de outros locais consequentemente maiores retenção de água nos microporos, na condição de solos não saturados, onde as forças capilares estarão presentes em baixas tensões.

\section{Conclusões}

A fração argila apresentou correlação com os atributos estruturais CC , PMP, Paeração Pt determinada, microp e macrop, contudo os atributos Paeração, microp, PMP foram os mais sensíveis na distinção dos ambientes de Cambissolo e Neossolo, enquanto no Latossolo e Chernossolo destacaram-se a areia total (AT) e o silte respectivamente.

O Neossolo Flúvico e o Chernossolo apresentaram similaridade quanto à retenção de água, função da fração argila, enquanto o Latossolo e Chernossolo se distanciaram quanto à retenção devido a areia e silte respectivamente.

\section{Referências}

DEBNATH, P.; DEB, P.; SEN, D.; PATTANNAIK, S. K.; SAH, D.; GHOSH, S. K. Physicochemical properties and its relationship with water holding capacity of cultivated soils along altitudinal gradient in Sikkim. International Journal of Agriculture Environment \& Biotechnology, v. 5, n. 2, p. 161-166, 2012.

KLEIN, C.; KLEIN, V. Ant. Estratégias para potencializar a retenção e disponibilidade de água no solo. Revista Eletrônica em Gestão, Educação e Tecnologia Ambiental, v. 19, n. 1, p. 21-29, 2015. 
LIBARDI, P. L. Dinâmica da água no solo. 2. ed. São Paulo: Universidade de São Paulo. 346p. 2012.

MOTA, J. C. A.; ASSIS JÚNIOR, R. N.; AMARO FILHO, J. P.; LIBARDI, L. Algumas propriedades físicas e hídricas de três solos na chapada do Apodi, RN, cultivados com melão. Revista Brasileira de Ciência do Solo, v. 32, 2008.

PARAHYBA, R. B. V.; ALMEIDA, B. G. de; ROLIM NETO, F. C.; ARAÚJO, M. do S. B. de; SILVA, M. S. L. Retenção de água em solos arenosos da Bacia Sedimentar do Tucano, Bahia. In: Congresso Brasileiro de Ciência do Solo, 15., 2015, Natal. Anais Eletrônicos.. Natal: CBCS, 2015.

REICHARDT, K. A água em sistemas agrícolas. São Paulo: Ed. Manole Ltda. Cap. 3, p. 27 -65, 1990. 